\title{
BMJ Open Congenital anomalies and associated risk factors in a Saudi population: a cohort study from pregnancy to age 2 years
}

Ahmed M Kurdi, ${ }^{1}$ Muhammad Ali Majeed-Saidan, ${ }^{2}$ Maha S Al Rakaf, ${ }^{1}$
Amal M AlHashem, ${ }^{2}$ Lorenzo D Botto, ${ }^{3}$ Hassan S Baaqeel, ${ }^{4}$ Amer N Ammari ${ }^{2}$

To cite: Kurdi AM, MajeedSaidan MA, Al Rakaf MS, et al. Congenital anomalies and associated risk factors in a Saudi population: a cohort study from pregnancy to age 2 years. BMJ Open 2019;9:e026351. doi:10.1136/ bmjopen-2018-026351

\section{- Prepublication history and} additional material for this paper are available online. To view these files, please visit the journal online (http://dx.doi. org/10.1136/bmjopen-2018026351).

Received 28 August 2018 Revised 19 May 2019 Accepted 30 July 2019

Check for updates

(C) Author(s) (or their employer(s)) 2019. Re-use permitted under CC BY-NC. No commercial re-use. See rights and permissions. Published by BMJ.

${ }^{1}$ Obstetrics \& Gynecology, Prince Sultan Military Medical City, Riyadh, Al Riyadh, Saudi Arabia ${ }^{2}$ Paediatrics, Prince Sultan Military Medical City, Riyadh, Saudi Arabia

${ }^{3}$ Department of Pediatrics, University of Utah, Salt Lake City, Utah, USA

${ }^{4}$ College of Medicine, King Saud bin Abdulaziz University for Health Sciences, Jeddah, Saudi Arabia

Correspondence to

Dr Ahmed M Kurdi;

ahmedkurdi1950@gmail.com

\section{ABSTRACT}

Objective To assess the three key issues for congenital anomalies (CAs) prevention and care, namely, CA prevalence, risk factor prevalence and survival, in a longitudinal cohort in Riyadh, Saudi Arabia.

Setting Tertiary care centre, Riyadh, Saudi Arabia. Participants Saudi women enrolled during pregnancy over 3 years and their 28646 eligible pregnancy outcomes (births, stillbirths and elective terminations of pregnancy for foetal anomalies). The nested case-control study evaluated the CA risk factor profile of the underlying cohort. All CA cases (1179) and unaffected controls (1262) were followed through age 2 years. Referred mothers because of foetal anomaly and mothers who delivered outside the study centre and their pregnancy outcome were excluded.

Primary outcome measures Prevalence and pattern of major CAs, frequency of CA-related risk factors and survival through age 2 years.

Results The birth prevalence of CAs was 412/10 000 births $(95 \% \mathrm{Cl} 388.6$ to 434.9$)$, driven mainly by congenital heart disease (148 per 10000$)(95 \% \mathrm{Cl} 134$ to 162$)$, renal malformations $(113,95 \% \mathrm{Cl} 110$ to 125$)$, neural tube defects (19, $95 \% \mathrm{Cl} 25.3$ to 38.3 ) and chromosomal anomalies $(27,95 \% \mathrm{Cl} 21$ to 33$)$. In this study, the burden of potentially modifiable risk factors included high rates of diabetes $(7.3 \%, 0 \mathrm{R} 1.98,95 \% \mathrm{Cl} 1.04$ to 2.12$)$, maternal age $>40$ years $(7.0 \%, 0 \mathrm{R} 2.1,95 \% \mathrm{Cl} 1.35$ to 3.3$)$, consanguinity (54.5\%, $\mathrm{OR} 1.5,95 \% \mathrm{Cl} 1.28$ to 1.81$)$. The mortality for live births with CAs at 2 years of age was $15.8 \%$.

Conclusions This study documented specific opportunities to improve primary prevention and care. Specifically, folic acid fortification (the neural tube defect prevalence was $>3$ times that theoretically achievable by optimal fortification), preconception diabetes screening and consanguinity-related counselling could have significant and broad health benefits in this cohort and arguably in the larger Saudi population.

\section{INTRODUCTION}

Because of their lifelong impact on health and survival, congenital anomalies (CAs) are increasingly recognised as a global health priority. ${ }^{12}$ With better control of infections
Strengths and limitations of this study

- Babies with congenital anomalies (CAs) are diagnosed prospectively, prenatally and postnatally and followed up to 2 years of age.

- Involvement of multidisciplinary teams in establishing the final diagnosis.

- Inclusion of elective termination of pregnancies with lethal CAs and stillbirths.

- Single-centre study. The pregnancy cohort was mainly from families of Saudi army personnel dependents, which could be a limiting factor.

and other causes of early mortality, CAs are becoming increasingly important drivers of child survival and health in low- and middle-income countries. ${ }^{1}{ }^{3}$ CAs affect approximately an estimated 1 in 33 newborns, contribute each year to 300000 deaths in the first month of life and are associated with 3.2 million birth-related disabilities. ${ }^{3}$ Accordingly, the World Health Assembly has emphasised the urgent need for action to help prevent, diagnose and provide timely interventions. ${ }^{1}$ Data on the prevalence and mortality associated with CAs are scarce in many low- and middle-income countries, with most reports originating in high-income areas. For example, in a population-based study of live births with CAs in the UK, the 20-year survival rate was $85.5 \% .^{4}$ Similarly, the 25-year survival rate among live births with CAs in New York state was $82.5 \%,{ }^{5}$ with a documented improvement from the 1980s (78.1\% from 1983 to 1988 ) to the early 2000 s (89.3\% from 2001 to 2006). Among CAs, the major drivers of mortality were cardiovascular anomalies $(51.1 \%)$ and chromosomal anomalies $(33.1 \%)$. In Korea, infant mortality among babies with CAs was 6.8/10 000 live births, and foetal mortality was 13.5/10 000 total births. ${ }^{6}$ 
However, local action, whether focused on primary prevention or on improving care, is most effective when based on reliable information about the key indicators of the causes and outcomes of CAs in the underlying population. In this study, we implemented an integrated approach to generate these data in a systematic cohort of women, tracked from mid-gestation through the second year of life of their children, to assess the prevalence of CAs, the burden of potentially modifiable risk factors and the survival of affected children, as a basis for better prevention and care. ${ }^{7}$

\section{METHODS}

\section{Setting}

The Prince Sultan Military Medical City (PSMMC) is a tertiary teaching institution with 1250 beds and approximately 10000 annual deliveries. PSMMC primarily serves Saudi army personnel and their families and is a referral centre for the other 16 military hospitals in the Kingdom of Saudi Arabia. The foetal medicine unit includes advanced imaging facilities, including three-dimensional and four-dimensional scanning. The paediatric department includes all major subspecialities, including medical genetics, paediatric surgery and paediatric cardiology.

\section{Study design}

This is an observational, prospective cohort study with a nested case-control study. The eligible cohort includes pregnancies of women who had their antenatal care and their routine antenatal anomaly ultrasound scan (USS) examination between 18 weeks and 22 weeks of gestation at PSMMC from 1 July 2010 through 30 June 2013 (figure 1).

In addition, Saudi women who are eligible for their antenatal care at PSMMC, but who did not have an antenatal screening ultrasound examination and later delivered at PSMMC, are also included in the study.

\section{Inclusions and exclusions}

Pregnancy outcomes included in the study were live births, stillbirths (foetal deaths at 20 weeks' gestation or later) and elective terminations of pregnancy for foetal anomalies (ETOPFAs). The study excluded spontaneous abortions, pregnancies referred from other hospitals because of a diagnosis of a foetal anomaly and babies with CAs delivered elsewhere and referred to PSMMC for evaluation and management.

\section{Evaluations}

Initial antenatal screening tests included a complete blood count, liver and kidney function tests, blood group

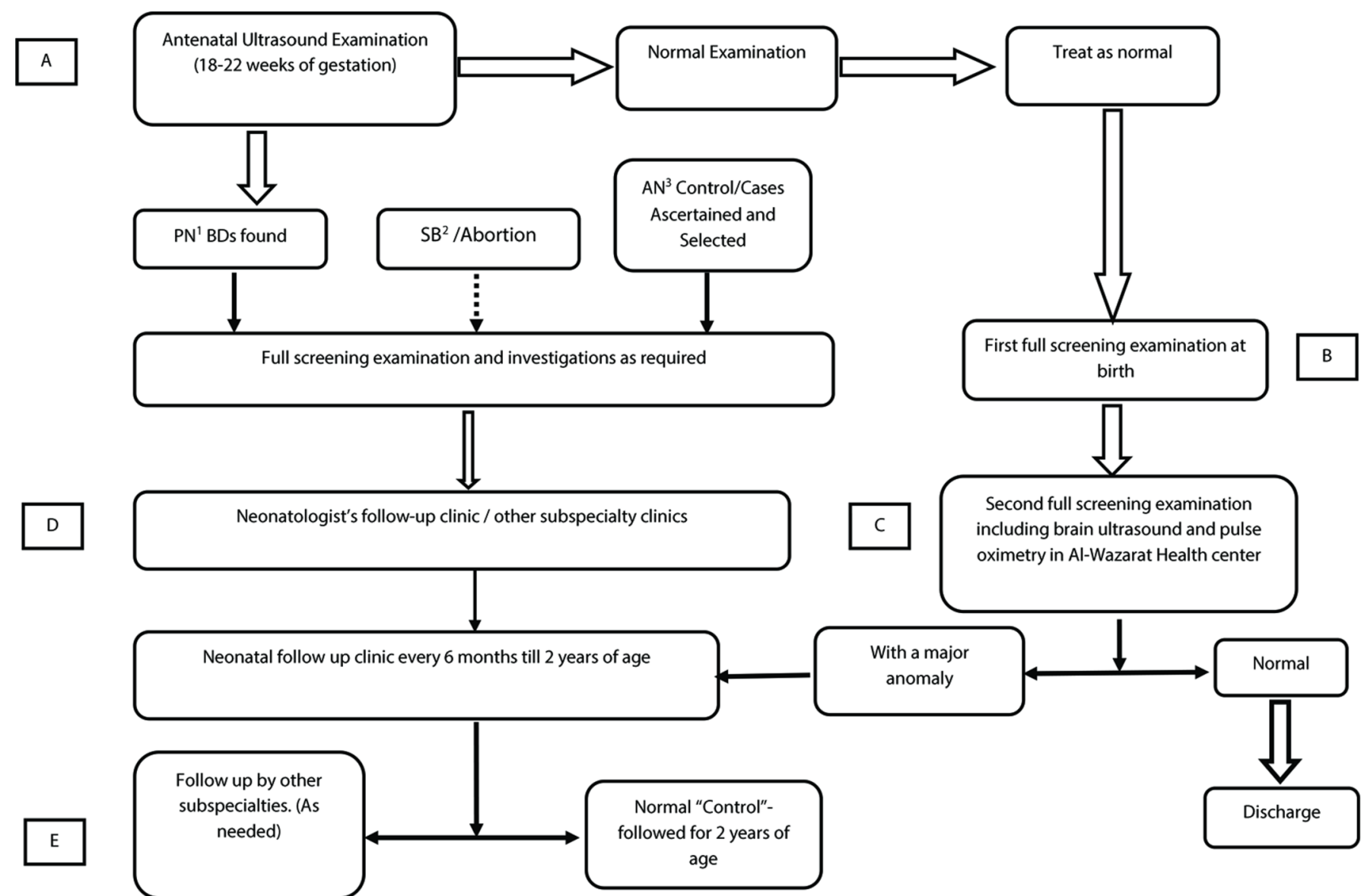

Figure 1 Catchment site and the study flow chart. Case catchment areas (A to E). A, antenatal clinic; B, at birth; C, the "onemonth clinic"; D, geneticist "one-month clinic" and E, other areas. 1, 2, 3 are postnatal, stillbirth and antenatal respectively. AN, antenatal; BD, birth defect; PN, postnatal; SB,stillbirth. 
and antibody screening, rubella and Toxoplasma status, hepatitis B screen, random blood sugar and glycated haemoglobin (HbA1c) levels, Venereal Disease Research Laboratory (VDRL, sickle cell screen and urine analysis. A glucose tolerance test was performed at 24 to 28 weeks of gestation.

When a structural birth defect was diagnosed or suspected antenatally, mothers were counselled by one of the investigators (MSR, AMK), demographic and exposure information was gathered and both parents were scheduled within 2 to 4 weeks to attend a dedicated clinic developed for the study. At that time, a detailed diagnostic and care plan was developed, which may have included further blood tests and foetal imaging, or amniocentesis, chorionic villous and/or foetal blood sampling for genetic studies. Consent was requested for cord blood collection for future molecular testing.

On the first day of life, all newborns in the cohort (with and without CAs) were examined by a paediatrician as part of the first clinical screening examination. Babies with CA, whether identified antenatally or postnatally, underwent diagnostic investigations as clinically indicated (eg, echocardiogram, cardiac catheterisation or other imaging studies; metabolic and molecular testing) and were referred to the appropriate subspecialists. A clinical geneticist evaluated all babies with suspected syndromes or multiple CAs. A letter was distributed to all clinical departments describing the study and requesting that they inform the study team about all infants and children with CAs born at PSMMC.

\section{Evaluations for specific congenital anomalies}

If congenital heart disease (CHD) was detected or suspected antenatally on USS examination, the mother was referred to the paediatric cardiologist for a foetal echocardiogram. All these infants were also re-evaluated after birth by a paediatric cardiologist. Isolated atrial septal defects (ASDs II) were re-evaluated at 6 to 12 months of age, and if the echocardiogram showed no evidence of ASD II at the time, the infant was not considered a case. Congenital hydronephrosis (HN) was graded using the Society of Foetal Urology grading system. ${ }^{8}$ Babies with grade $1 \mathrm{HN}$ were given a repeat USS examination within the first year of life; if $\mathrm{HN}$ had resolved, the baby was not considered a case. Chromosomal analysis was performed according to standard procedures, and a minimum of 20 metaphases were analysed (Applied Imaging CytoVision Karyotyping System). Reports followed the International System of Human Cytogenetic Nomenclature (ISCN 2013). Molecular studies were performed at the Biocenthia Health Group in Germany (http://www.bioscientia. $\mathrm{de} / \mathrm{en} /$ ), the Mayo Medical Laboratories in the USA and at the Developmental Genetic Laboratory at King Faisal specialist hospital and research centre in Saudi Arabia.

\section{Nested case-control study}

The nested case-control study included as cases all women in the cohort with a pregnancy diagnosed with a CA and as controls a random sample of women in the cohort with a normal USS. The random sample was generated daily by taking the morning list of scheduled USS and using a random number generator (http://www.random.org) to select potential controls so that the control sample would eventually be at least as large as the estimated total number of cases. If a woman initially selected as a control had a pregnancy diagnosed with a birth defect at the initial date or later, she was then included in the case group. Investigators administered an in-person structured interview to case and control mothers. The interview included information about age (for both parents), weight before pregnancy, height, parity, family income (father's income or combined parental income if the mother worked), maternal education level (illiterate, primary school graduate, secondary school graduate or university graduate), parental occupation (mother; housewife, teacher, student and others, father; soldier, officer or civilian employee), folic acid (FA) supplement use (regular use before and during the first trimester of pregnancy, irregular or only postconception use, no use or uncertain use as per the mother's report), parental smoking (one or both parents smoking during the current pregnancy), maternal radiation exposure during the first trimester, maternal diabetes (overt or gestational) as defined by the International Association of Diabetes and Pregnancy study groups ${ }^{9}$ and HbA1c level, family history of CAs (in previous pregnancies and in maternal or paternal lineages), drug and medication use during the first trimester and chronic maternal systemic illnesses (hypothyroidism, epilepsy, depression, essential hypertension and bronchial asthma). Consanguinity was defined as women being first or second cousins to their husbands (online supplementary file).

\section{Follow-up}

Case infants and control infants were examined in the dedicated study clinic at 1, 6, 12, 18 and 24 months of age. Two neonatologists and a clinical geneticist supervised the clinic. Babies with CAs also continued to be followed by the relevant subspeciality clinics. The remaining cohort (babies without CAs not selected as controls) was re-examined at 4 to 8 weeks by the paediatrician for a second screening examination. A head ultrasound and a postductal pulse oximetry reading were completed in all babies attending the clinics. If the oxygen saturation was below $95 \%$, the baby was referred to the paediatric cardiologist for evaluation. If any CAs were detected at the second screening examination, the babies were referred to the genetics clinic for further evaluation and diagnosis. If the second screening examination proved to be normal, then no further follow-up was arranged. However, if CAs were discovered later in babies up to 2 years of age, they were included in the study.

\section{Case review, coding, classification}

Congenital anomalies were coded following the International Statistical Classification of Diseases and Related 
Health Problems, $10^{\text {th }}$ revision, (ICD10, WHO-2010) according to the European Concerted Action on Congenital Anomalies and Twins (EUROCAT) recommended procedures. ${ }^{10}$ We did not include isolated minor anomalies or prematurity-related conditions such as patent ductus arteriosus or hydrocephalus complicating intraventricular haemorrhage diagnosed in preterm babies ( $<37$ completed weeks of gestation). Data were entered in a version of EUROCAT Data Management Program modified to include control records and the additional variables generated by the case-control study and the follow-up.

\section{Statistical analysis}

The data collected and used in this study was part of our routine care and was anonymised.

ORs for the association between risk factors and CAs were estimated using multiple logistic regression in a two-step process. An initial set of variables was selected by univariate logistic regression as being associated with CA risk $(p<0.05)$. Variables highly correlated with other variables (eg, insulin use) were not entered into the model. This initial variable set was then reduced by stepwise backward elimination to produce a more parsimonious model. The final model retained the following covariates: consanguinity, maternal age group, education level, diabetes and history of siblings with a congenital anomaly. The model fit was assessed with the Hosmer and Lemeshow's goodness of fit test and by calculating
Nagelkerke $\mathrm{R}^{2}$. Statistical analysis was performed with SPSS for Windows, V.15 (SPSS Inc, Chicago, Illinois).

\section{Patient and public involvement}

Our long-term experience with the families and their offspring has helped us to shape the research question and the study design. All families recruited were informed about the study objectives. None of the parents were involved in the study design, recruitment to and conduct of the study. The study results were disseminated to the community and to the professional healthcare provider through social media, newspapers, presentation at various conferences and scientific publications.

\section{RESULTS}

Of the 31032 birth outcomes of the 30351 women followed since pregnancy, $30753(99 \cdot 1 \%)$ occurred at PSMMC (figure 2). Of these, 2107 were spontaneous abortions $(6 \cdot 8 \%)$ and were not included in the study, leaving 28646 eligible births (27 726 singleton births and 920 multiple births). The overall stillbirth rate was slightly less than $1 \%$ (figure 2 ).

\section{Birth defect occurrence, detection and mortality}

Of the 28646 eligible pregnancy outcomes, 1179 were diagnosed with a CA, for an overall prevalence of 412/10 000 (95\% CI 388.6 to 434.9 ) total births, or 1 in 24 births. Of these 1179 cases, $38(3.2 \%)$ were stillbirths, and $18(1.5 \%)$

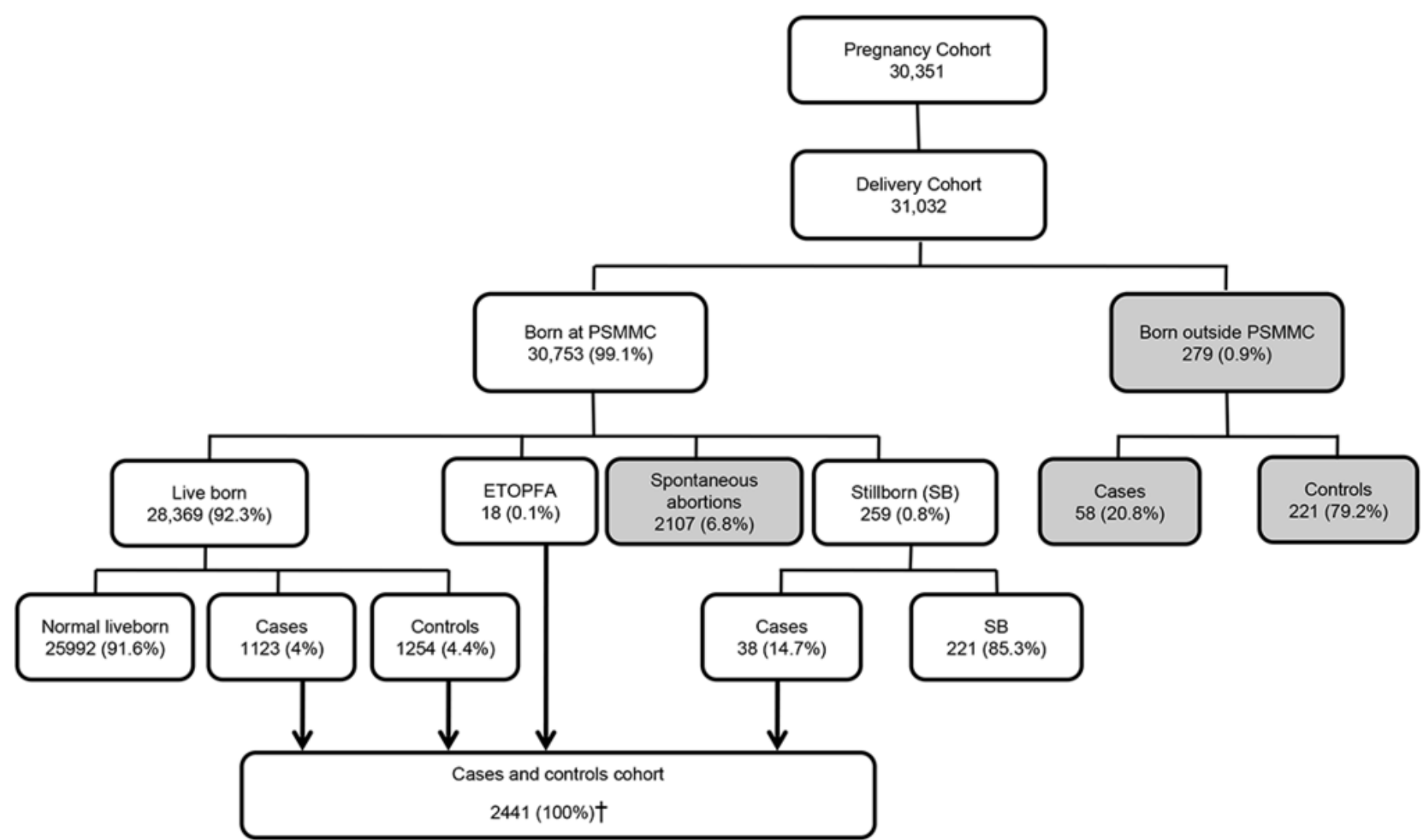

Figure 2 Study population and distribution of pregnancies and their outcomes. PSMMC, Prince Sultan Military Medical City; ETOPFA, elective terminations of pregnancy for foetal anomalies. †Eight control foetuses were stillbirth. 
were electively terminated because of lethal malformations (13 with anencephaly, 3 with severe hydrops foetalis and cystic hygroma, 1 with Meckel-Gruber syndrome and 1 with bilateral renal agenesis) (table 1). The antenatal detection rate among women who has had an antenatal ultrasound screening examination was $70.6 \%$ (561/795). In $90 \%$ of these cases $(505 / 561)$, the diagnosis was made by ultrasound scan at 22 weeks of gestation or later. Of the 618 babies diagnosed postnatally, $296(47.9 \%)$ were diagnosed at birth, 239 (38.7\%) between 1 and 7 days, $29(4.7 \%)$ between 1 and 4 weeks, $52(8.4 \%)$ between 1 and 12 months and $2(0.3 \%)$ after 1 year of age. Mortality among live births with CAs (table 1) was $14.1 \%$ in the first year, nearly half of which occurred in the first week of life, with a total mortality of $15.8 \%$ by the end of the second year of life. Mortality at 2 years was $0.9 \%$ in the unaffected cohort $(0.24 \%$ for live births). Among the controls, there were eight stillbirths, two deaths because of prematurity and its complications and one death at 2 years of age because of acute fulminating leukaemia.

\section{Contribution of specific congenital anomalies}

Approximately half of the overall birth prevalence was due to congenital heart disease and central nervous system anomalies. Neural tube defects occurred at a rate of 19 per 10000 (95\% CI 13.8 to 23.9) (1 in 526 births). Severe CHD occurred at a rate of 32 per 10000 (95\% CI 25.3 to 38.3) (1 in 313 births) and accounted for $21.4 \%$ of all CHD cases. Chromosomal anomalies whose risk is associated with increased maternal age (trisomies 21, 18 and 13) occurred with a combined prevalence of 25 per 10000 (95\% CI 19.6 to 31.3) (1 in 392 births). Trisomy 21 accounted for most cases of chromosomal anomalies, with a prevalence of 22 per 10000 (95\% CI 16.7 to 27.4) or 1 in 456 births (table 2).

Two-thirds of all cases of CAs $(773 / 1179,65.6 \%)$ were isolated (eg, they involved a single body system) (table 3).

\section{Risk factors}

As a proxy of risk factor prevalence in the underlying population, we used the frequency of selected maternal or parental risk factors for CAs among controls in the nested case-control study (figure 3). The most frequent potentially modifiable factors included lack of periconception folic acid supplement use, consanguinity, high body mass index, advanced maternal age, smoking (first or secondhand) and maternal diabetes. Nearly $6 \%$ of non-primiparous women had one prior child with a major CA. In the univariate analysis, the nested case-control study (table 4) detected overall increased ORs for all CAs combined for consanguinity, advanced maternal age, high parity, maternal illiteracy, maternal university education, X-ray exposure during pregnancy, maternal diabetes and positive family history of CA in a sibling. Increased ORs with CIs, including unity, were also found for maternal depression and hypertension (table 4). In the multiple logistic regression model, only first-degree consanguinity (OR 1.5, 95\% CI 1.28 to 1.81 ), maternal

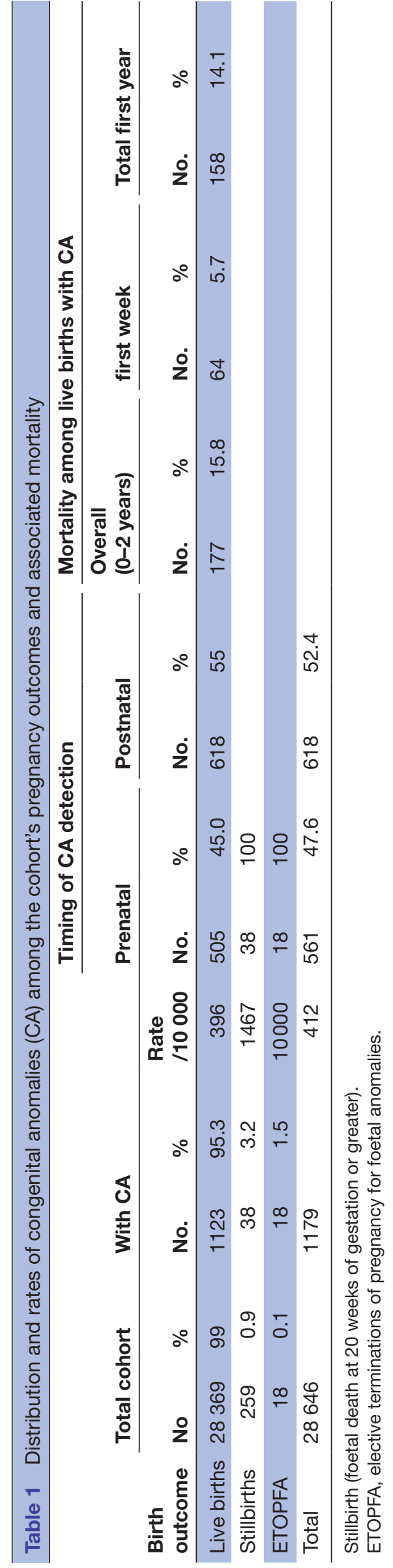



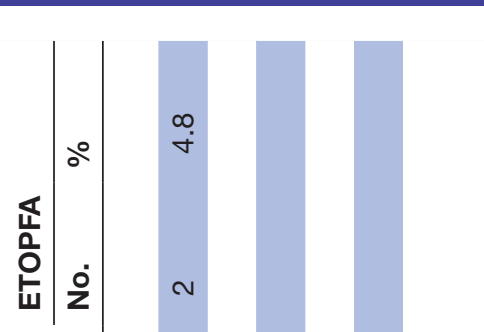


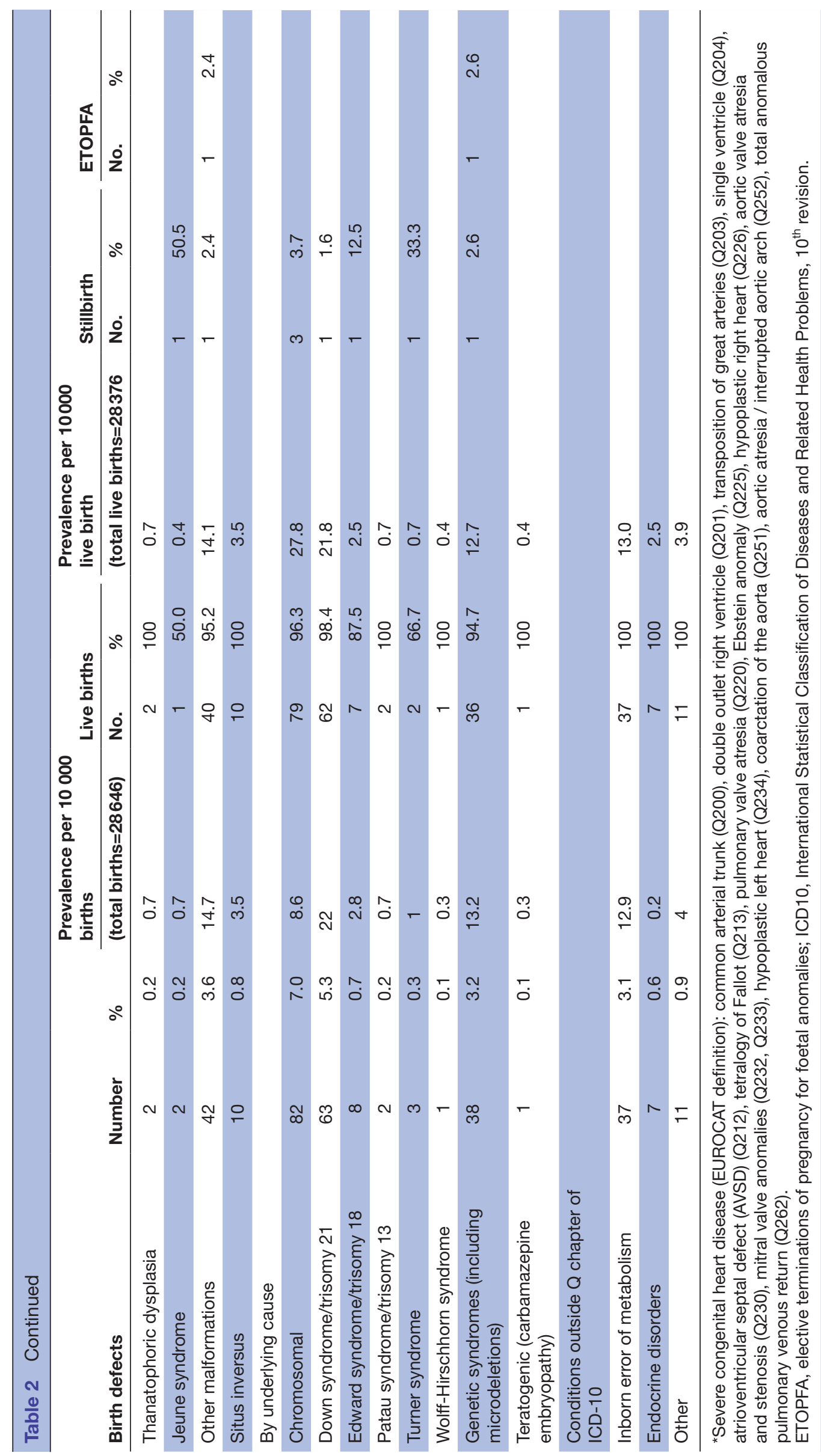


Table 3 Common single congenital anomalies (CA) per body system involved

\begin{tabular}{|c|c|c|c|c|}
\hline \multirow[b]{2}{*}{ Body system } & \multirow{2}{*}{$\begin{array}{l}\text { Total number } \\
\text { Of CA }\end{array}$} & \multicolumn{2}{|c|}{ Isolated CA } & \multirow[b]{2}{*}{ Common isolated anomalies } \\
\hline & & No. & $\%$ & \\
\hline Cardiovascular & 424 & 265 & 62.5 & $\begin{array}{l}\text { Ventricular septal defects in } 75(28.3 \%) \text {. } \\
\text { Atrial septal defects in } 67(25.3 \%) \text {. } \\
\text { Pulmonary valve atresia and stenosis in } 18(6.8 \%) \text {. } \\
\text { Severe CHD in } 54(20.4 \%)\end{array}$ \\
\hline Urinary & 323 & 229 & 70.8 & $\begin{array}{l}\text { Congenital hydronephrosis in } 147 \text { (64.2\%). } \\
\text { Bilateral renal agenesis in } 3(1.3 \%) \text {. }\end{array}$ \\
\hline Central nervous & 161 & 68 & 42.8 & $\begin{array}{l}\text { Neural tube defects in } 32(47.1 \%) \text {. } \\
\text { Encephalocele in } 4(5.9 \%)\end{array}$ \\
\hline Gastrointestinal & 74 & 33 & 44.6 & $\begin{array}{l}\text { Ano-rectal atresia and stenosis in } 16 \text { (48.5\%). } \\
\text { Diaphragmatic hernia in } 6 \text { (18.2). }\end{array}$ \\
\hline Limb & 97 & 31 & 32 & $\begin{array}{l}\text { Total limbs reduction in } 9(29 \%) \text {. } \\
\text { Upper limb reduction in } 7(22.6 \%) \text {. } \\
\text { Lower limb reduction in } 3(9.7 \%) \text {. }\end{array}$ \\
\hline
\end{tabular}

$\mathrm{CHD}$, congenital heart disease.

age of more than 40 years (OR 2.1, 95\% CI 1.35 to 3.3 ), maternal illiteracy (OR 1.4, 95\% CI 1.17 to 1.7 ), maternal university level education, (OR 1.74, 95\% CI 1.24 to 2.44 ), maternal diabetes mellitus (OR 1.98, 95\% CI 1.33 to 2.95) and history of a sibling with an anomaly (OR 1.49, 95\% CI 1.04 to 2.12) were retained in the model (table 5). The Hosmer and Lemeshow goodness of fit $p$ value was 0.08 , and Nagelkerke $\mathrm{R}^{2}$ was 0.055 , explaining $6 \%$ of the effect on CAs.

Of the 223 mothers with diabetes mellitus (DM) who had CA-affected foetuses $(223 / 1179,18.9 \%), 36(3 \%)$ had overt DM (ODM), and $187(15.7 \%)$ had gestational DM (GDM). Of the mothers with GDM, $50(26.7 \%)$ required insulin. Among the controls, 200 mothers had diabetes $(200 / 1179,15.8 \%)$, of whom $12(0.9 \%)$ had ODM, and $188(15.9 \%)$ had GDM. Of the latter, $29(14.5 \%)$ required insulin.

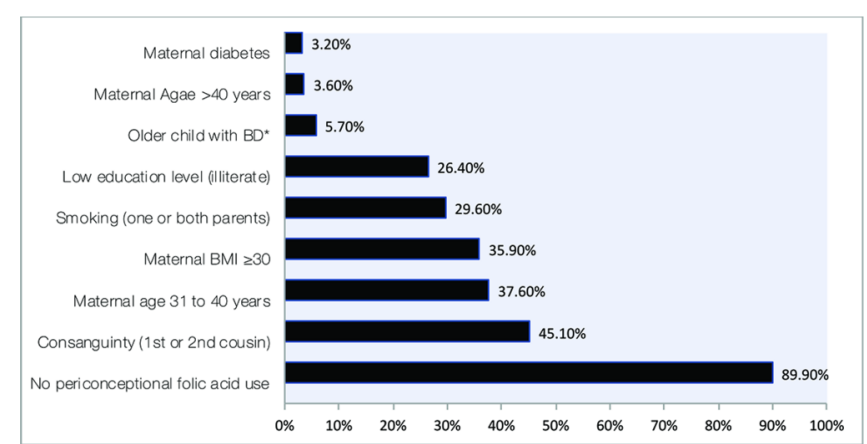

Figure 3 Frequency among control subjects of selected risk factors for $\mathrm{CA}$. *Frequency of prior child with $\mathrm{BD}$ computed among non-primiparous women. BD,birth defect; BMI, pre-pregnancy maternal body mass index; CAs, congenitalanomalies.
Maternal age over 40 years was high at $7 \%$ among mothers of babies with CA compared with 3.6\% among controls mothers (OR 2.09, 95\% CI 1.43 to 3.05, $\mathrm{p}=0.0002$ ) (table 4). This was mainly due to chromosomal aneuploidy. Further subgroup analysis showed non-chromosomal anomalies (NCA) was found in 55 mothers $(4.6 \%)$ compared with $3.6 \%$ among the controls mothers (OR $1.29,95 \%$ CI 0.86 to $1.9, p=0.2)$. The main NCA found were CHD in 22 (40\%), 7 (12.7\%) were severe CHD and neural tube defects in $5(9.1 \%)$.

\section{DISCUSSION}

This longitudinal study of CAs in a pregnancy cohort in Saudi Arabia, followed from mid-gestation through age 2 years, had three integrated aims: to describe the population's risk factor profile, document the associated birth prevalence of CAs and assess survival as a critical health outcome. $^{7}$ Gathering information about these three critical areas is crucial when planning and evaluating policies and interventions, be they aimed at primary prevention (eg, folic acid fortification to prevent neural tube defects) or at improving care.

The burden of CAs was high in this population. The study documented a remarkably high birth prevalence of CAs of 412 per 10000 or 1 in 24 total births. This rate is higher than that reported in studies from many high-income countries, as those reported by EUROCAT (261/10 000 births),${ }^{11}$ British Isles Network of Congenital Anomaly Registers (BINOCAR) (206/10 000 births $)^{12}$ and the Bradford study $\left(305 / 10\right.$ 000).$^{13}$ This prevalence of CAs is also higher than that previously reported from Saudi Arabia (115 to 257 per 10000 live births) ${ }^{14-16}$ Although some studies report an even higher 
Table 4 Distribution of parental sociodemographic characteristics and association with congenital anomaly risk (univariate analysis)

\section{Controls (total}

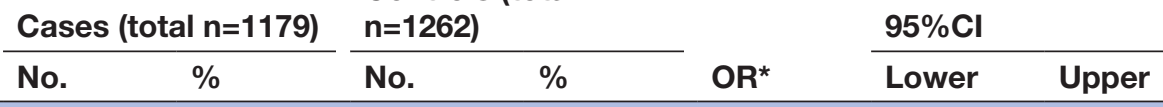

\section{Variable}

$537 \quad 45.5$

693

54.9

Ref

Consanguineous

642

54.5

569

45.1

1.53

1.30

1.8

Maternal age (years)

\begin{tabular}{|c|c|c|c|c|c|c|c|}
\hline$<20$ & 24 & 2.0 & 48 & 3.8 & 0.58 & 0.35 & 0.96 \\
\hline 20-30 & 599 & 50.8 & 694 & 55.0 & Ref & - & - \\
\hline $31-40$ & 473 & 40.1 & 474 & 37.6 & 1.16 & 0.98 & 1.37 \\
\hline$>40$ & 83 & 7.0 & 46 & 3.6 & 2.09 & 1.43 & 3.05 \\
\hline \multicolumn{8}{|c|}{ Paternal age (years) } \\
\hline $20-30$ & 341 & 28.9 & 403 & 31.9 & 0.92 & 0.76 & 1.10 \\
\hline $31-40$ & 548 & 46.5 & 593 & 47.0 & Ref & - & - \\
\hline $41-50$ & 240 & 20.4 & 225 & 17.8 & 1.15 & 0.93 & 1.43 \\
\hline$>50$ & 50 & 4.2 & 41 & 3.2 & 1.32 & 0.86 & 2.03 \\
\hline \multicolumn{8}{|c|}{ Maternal body mass index* } \\
\hline$<18.5$ & 24 & 2.1 & 35 & 2.8 & 0.75 & 0.44 & 1.29 \\
\hline $18.5-24.99$ & 324 & 27.8 & 388 & 30.8 & 0.91 & 0.74 & 1.12 \\
\hline $25.0-29.99$ & 352 & 30.2 & 385 & 30.5 & Ref & - & - \\
\hline$\geq 30$ & 464 & 39.9 & 453 & 35.9 & 1.12 & 0.92 & 1.36 \\
\hline \multicolumn{8}{|c|}{ Previous deliveries (parity) } \\
\hline Nulliparous & 216 & 18.3 & 273 & 21.6 & 0.92 & 0.74 & 1.16 \\
\hline Para 1-2 & 374 & 31.7 & 436 & 34.5 & Ref & - & - \\
\hline Para 3-4 & 283 & 24.0 & 273 & 21.6 & 1.21 & 0.97 & 1.50 \\
\hline Para $\geq 5$ & 306 & 26.0 & 280 & 22.2 & 1.27 & 1.03 & 1.58 \\
\hline
\end{tabular}

Family monthly income Saudi riyals (US\$)

\begin{tabular}{|c|c|c|c|c|c|c|c|}
\hline$<3000$ SR $(<800 \$)$ & 19 & 1.9 & 12 & 1.0 & 1.87 & 0.89 & 3.92 \\
\hline 10000-14 000SR (2667-3999\$) & 235 & 23.2 & 277 & 22.3 & Ref & - & - \\
\hline 3000-6999SR (800-1866\$) & 232 & 22.9 & 291 & 23.4 & 0.94 & 0.74 & 1.20 \\
\hline 7000-9999SR (1867-2666\$) & 367 & 36.3 & 496 & 39.9 & 0.87 & 0.70 & 1.09 \\
\hline$\geq 15000(\geq 4000 \$)$ & 158 & 15.6 & 167 & 13.4 & 1.12 & 0.84 & 1.47 \\
\hline \multicolumn{8}{|l|}{ Maternal education } \\
\hline Illiterate & 391 & 33.2 & 333 & 26.4 & 1.50 & 1.26 & 1.80 \\
\hline Schooling up to high school & 671 & 56.9 & 859 & 68.1 & Ref & - & - \\
\hline University & 117 & 9.9 & 70 & 5.5 & 2.05 & 1.49 & 2.81 \\
\hline \multicolumn{8}{|l|}{ Folic acid intake } \\
\hline Periconceptional & 109 & 9.2 & 128 & 10.1 & Ref & - & - \\
\hline Improper use† & 1070 & 90.8 & 1134 & 89.9 & 1.04 & 0.79 & 1.36 \\
\hline \multicolumn{8}{|l|}{ Parental Smoking } \\
\hline Neither parent smoked & 837 & 71.0 & 888 & 70.4 & Ref & - & - \\
\hline One or both parents smoked & 342 & 29.0 & 374 & 29.6 & 0.97 & 0.82 & 1.16 \\
\hline \multicolumn{8}{|l|}{ Radiation exposure in pregnancy } \\
\hline None & 1161 & 98.5 & 1254 & 99.4 & Ref & - & - \\
\hline Radiation exposure in pregnancy & 18 & 1.5 & 8 & 0.6 & 2.43 & 1.05 & 5.61 \\
\hline
\end{tabular}


Table 4 Continued

\begin{tabular}{|c|c|c|c|c|c|c|c|}
\hline \multirow[b]{2}{*}{ Variable } & \multicolumn{2}{|c|}{ Cases (total $n=1179$ ) } & \multicolumn{2}{|c|}{$\begin{array}{l}\text { Controls (total } \\
n=1262 \text { ) }\end{array}$} & \multirow[b]{2}{*}{ OR $^{*}$} & \multicolumn{2}{|l|}{$95 \% \mathrm{Cl}$} \\
\hline & No. & $\%$ & No. & $\%$ & & Lower & Upper \\
\hline \multicolumn{8}{|l|}{ Diabetes mellitus } \\
\hline No DM & 956 & 81.1 & 1062 & 84.2 & Ref & - & - \\
\hline DM on insulin (all, overt \& gestational) & 86 & 7.3 & 41 & 3.2 & 2.34 & 1.60 & 3.43 \\
\hline Gestational DM on diet only & 137 & 11.6 & 157 & 12.6 & 0.91 & 0.62 & 1.16 \\
\hline \multicolumn{8}{|c|}{ Siblings of cases and controls (primiparous mothers excluded) } \\
\hline No affected sibling & 757 & 78.6 & 932 & 94.2 & Ref- & - & - \\
\hline Sibling with CA & 85 & 8.8 & 58 & 5.7 & 1.61 & 1.14 & 2.27 \\
\hline \multicolumn{8}{|l|}{ Medication use in pregnancy } \\
\hline None & 792 & 67.2 & 951 & 75.3 & - & - & - \\
\hline Thyroxin & 102 & 8.7 & 106 & 8.4 & 1.03 & 0.78 & 1.37 \\
\hline Insulin & 86 & 7.3 & 40 & 3.2 & 2.34 & 1.59 & 3.45 \\
\hline Methyldopa & 14 & 1.2 & 14 & 1.1 & 1.07 & 0.51 & 2.26 \\
\hline \multicolumn{8}{|l|}{ Maternal systemic illnesses } \\
\hline None & 808 & 68.5 & 971 & 76.9 & Ref- & - & - \\
\hline Mothers with hypothyroidism & 123 & 10.4 & 128 & 10.1 & 1.03 & 0.80 & 1.34 \\
\hline Mothers with bronchial asthma & 106 & 9.0 & 97 & 7.7 & 1.19 & 0.89 & 1.58 \\
\hline Mothers with depression & 12 & 1.0 & 6 & 0.5 & 2.15 & 0.81 & 5.75 \\
\hline Mothers with essential hypertension & 23 & 2.0 & 15 & 1.2 & 1.65 & 0.86 & 3.19 \\
\hline
\end{tabular}

Some families declined reporting their income.

*BMI not available for 15 mothers.

†Improper-use includes FA taken post conception in 49 mothers (43 case mothers and 6 six control mothers) who were not sure about their intake.

CA, congenital anomalies; DM, diabetes mellitus; SR, Saudi riyals.

prevalence, for example, such as an antenatal CA prevalence of 521/10 000 pregnancies screened, and a prevalence among live births of $465 / 10000,{ }^{17}$ these figures may be overestimates of the true prevalence because of the inclusion of mothers referred from other institutions. In the current study, we strove to obtain as complete an

Table 5 Multiple logistic regression model results for the significant risk factors on univariate analysis

\begin{tabular}{|c|c|c|c|c|c|c|}
\hline \multirow[b]{3}{*}{ Variable } & \multicolumn{3}{|c|}{$\begin{array}{l}\text { Adjusted OR (from multiple } \\
\text { logistic regression model)* }\end{array}$} & \multicolumn{3}{|c|}{$\begin{array}{l}\text { Crude OR (from univariate } \\
\text { analysis) }\end{array}$} \\
\hline & \multirow[b]{2}{*}{ OR } & \multicolumn{2}{|c|}{ 95\% C.I. } & \multirow[b]{2}{*}{ OR } & \multicolumn{2}{|c|}{ 95\% C.I. } \\
\hline & & Lower & Upper & & Lower & Upper \\
\hline Consanguinity, none (reference group) & - & - & - & - & - & - \\
\hline Consanguinity, first degree & 1.52 & 1.28 & 1.81 & 1.53 & 1.30 & 1.81 \\
\hline Maternal age, $20-30$ years (reference group) & - & - & - & - & - & - \\
\hline Maternal age, $<20$ years & 0.54 & 0.32 & 0.91 & 0.58 & 0.35 & 0.96 \\
\hline Maternal age, $>40$ years & 2.11 & 1.35 & 3.30 & 2.09 & 1.43 & 3.05 \\
\hline $\begin{array}{l}\text { Maternal education, up to high school (reference } \\
\text { group) }\end{array}$ & - & - & - & - & - & - \\
\hline Maternal education, illiterate & 1.41 & 1.17 & 1.70 & 1.50 & 1.26 & 1.80 \\
\hline Maternal education, university & 1.74 & 1.24 & 2.44 & 2.05 & 1.49 & 2.81 \\
\hline Diabetes on insulin, overt or gestational (yes/no) & 1.98 & 1.33 & 2.95 & 2.34 & 1.60 & 3.43 \\
\hline Sibling with anomalies (yes/no) & 1.49 & 1.04 & 2.12 & 1.61 & 1.14 & 2.27 \\
\hline
\end{tabular}

*Adjustment for consanguinity, maternal age, maternal education, diabetes mellitus, sibling with anomalies. 
ascertainment as possible by initiating follow-up in pregnancy and extending it through the second year of life, by including stillbirths and ETOPFAs, and by successfully including some genetic conditions that tend to be diagnosed after the newborn period.

However, the high prevalence of CAs is likely to be due not only to the completeness of the ascertainment but also to the high frequency of adverse risk factors in the underlying population, as documented in the controls of the nested case-control study. When focusing on factors that are potentially modifiable, three such factors seem to stand out. The first is insufficient folic acid use in this cohort $(<10 \%$ in the periconception period). The rate of neural tube defects was 19 per $10000 /$ births (table 2), at least three times higher than the rate of 6 per 10000 / births, which seems achievable by providing sufficient folic acid to women of childbearing age. ${ }^{18} 19$ Although legislation requiring the mandatory fortification of flour had been in place in Saudi Arabia for years prior to this study (Kingdom of Saudi Arabia, 2000; Food fortification initiative, 2013), ${ }^{202}$ our findings suggest that there are gaps in coverage or effectiveness, which could be evaluated with nutrition or blood folate surveys. Such information would provide important evidence to improve folate sufficiency in the population, with its attendant health benefits, including a substantial reduction in the burden of neural tube defects. Because of the inclusion of stillbirths and pregnancy terminations, this study also provides a fuller estimate of the potential benefits of primary prevention than if only live births had been identified (representing just over half of all cases, 30/54).

The second factor is maternal diabetes (tables 4 and 5). Diabetes is an established risk factor for many CAs, and diabetes control before conception has been shown to reduce and nearly normalise CA risk. ${ }^{922}{ }^{23}$ Several avenues for preventing diabetes and its health effects are available, including population screening (many diabetic women are undiagnosed), healthcare and counselling and education on healthy lifestyle and dietary choices starting from childhood. The current reported prevalence in Saudi Arabia of overt diabetes in women above age 40 years ranges from $7.7 \%$ to $21.7 \% .{ }^{24-26}$ In the study cohort, overt diabetes was observed in $2 \%$ of women and increased in women 30 years old or older. Al-Nozha and colleagues ${ }^{27}$ reported a prevalence of overt diabetes of $11.6 \%$ in women aged 30 to 39 years and $>22 \%$ in women aged $\geq 40$ years compared with $2.7 \%$ and $7.1 \%$ in our study, respectively. Though lower than these estimates, the prevalence of overt diabetes in the study cohort is alarmingly high.

Third, we observed a high rate of parental consanguinity $(54.5 \%)$, especially first-cousin marriages $(48.0 \%)$. These marriages are common in many parts of the Middle East, Africa and the Indian subcontinent, ${ }^{28-30}$ with one estimate suggesting that "one billion people live in communities with a preference for consanguineous marriage" (Hamamy, 2012). ${ }^{29}$ This preference has deep social roots. Nevertheless, education combined with preconception and premarital counselling can be important prevention strategies by focusing on increasing awareness to allow couples to make more informed choices. Close consanguinity is a known risk factor for CAs, ${ }^{30}$ as well as Mendelian conditions such as inborn errors of metabolism (occurring in 1 in 770 births in this study), as confirmed in prior reports from Saudi Arabia and from the world literature. ${ }^{31} 32$

Advanced maternal age (>40 years) was high $(7 \%)$ among mothers of babies affected with CA in the cohort studied. This is comparable to $6 \%$ among French mothers but higher than mothers from other 14 European countries (Loane et al, 2009). ${ }^{33}$ Advanced maternal age is increasing over the last two decades ${ }^{33} 34$ and is affecting the prevalence of aneuploidy. The risk for NCA were similar to controls and recent reports suggest that it has a protective effect. ${ }^{35}$ Several reports have shown a higher prevalence of specific CA among babies of mothers at this age group like neural tube defects, cleft lip, oesophageal atresia with or without tracheal fistula. We found a high prevalence of CHD and neural tube defects.

Structured health education programmes at several levels should emphasise the importance of planed pregnancies at the optimal age (20 to 30 years), ensure adequate periconceptional folic acid intake ( 400 to $800 \mu \mathrm{g}$ daily) ${ }^{36}$ and detailed foetal anomaly scan. A nation-wide CA registry will help to give a fuller picture and monitor the trends and the results of any intervention.

We did not diagnose cases of congenital rubella syndrome. This is likely due to the active immunisation programme in Saudi Arabia, with a measles, mumps and rubella vaccine uptake of $97 \%$. In addition, preschool age girls are given a booster vaccine against rubella.

In a prior publication, we reported a low regular (periconception) folic acid (FA) intake $(9.7 \%$ ) in this study population $^{37}$ and suggested fortification of rice in addition to wheat, complemented by education programmes supporting FA supplementation, as an efficient strategy to achieve folate sufficiency in the population.

Finally, our findings emphasise the impact of CAs in this population by documenting not only birth prevalence but also the associated early mortality (table 1), which was $15.8 \%$ by the second year of life (nearly all in the first year). Further supporting the high impact of CAs are the findings by Majeed-Saidan and colleagues ${ }^{38}$ who reported that $36 \%$ of deaths in a large neonatal intensive care unit in Riyadh were due to lethal CAs. These findings highlight the crucial importance and urgency to improve care in addition to primary prevention.

This study demonstrated the importance of the "triple surveillance' programme, suggested by Botto and Mastroiacovo, ${ }^{4}$ for identifying the risk factors for CAs (causes), estimating the burden of the disease (prevalence) and assessing disease outcome (mortality). This will ultimately lead to disease burden reduction or prevention by instituting appropriate interventions.

The study has limitations. Because of the cohort design, the resulting sample size did not allow a more detailed analysis of specific CA groups. Estimates of some key risk factors, such as folic acid insufficiency, were based on 
maternal reports (eg, reported supplement use) rather than biomarkers. Furthermore, the pregnancy cohort was mainly from families of Saudi army personnel dependents. Although the Saudi Army recruits from all sectors of Saudi society, a broader survey of the Saudi population would provide additional information to better assess gaps and opportunities for prevention and care nationwide.

\section{CONCLUSION}

This longitudinal surveillance programme that encompassed the causal chain from risk factors to health outcomes documented several opportunities to reduce the burden of CAs through primary prevention and better care. Folic acid fortification, preconception diabetes screening and consanguinity-related counselling could have significant health benefits in this cohort and arguably in the larger Saudi population, particularly if associated with a national CA monitoring programme to support and track the impact of interventions.

Acknowledgements We thank the Medical Services Directorate of the Saudi Armed Forces and the PSMMC directorate for their support during the initiation and execution of the study; the study's advisory board (Eduardo Castilla, Pierpaolo Mastroiacovo, Ester Garne, Fowzan Alkuraya and Wesam Kurdi) for advice and guidance throughout the study and the study secretaries for their commitment and enthusiasm.

Contributors AMK, study conception and design, revised the manuscript. MAMS, study conception and design, drafting and revising the manuscript. MSR, study design and data collection. AMH, data collection and revised the manuscript. LDB, study design and critically revised the manuscript for intellectual content. HSB, statistical analysis and revised the manuscript. ANA, study design, data collection, revised the manuscript. All authors approved the submission of the manuscript.

Funding This project was supported by a generous grant from King Abdul-Aziz City for Science and Technology (KACST) through the National Science, Technology and Innovation Plan (NSTIP). Project No: 09-MED748-21.

Disclaimer The funding institution had no role in the study design, data collection, analysis, interpretation of data, the writing of the various reports or the decision for submission for publication. All authors have full independence from the funder, have full access to the data in the study and take full responsibility for the integrity of the data and the accuracy of the analysis.

Competing interests None declared.

Patient consent for publication Not required.

Ethics approval The study was approved by the Ethical Committee of the PSMMC (Project No. 366, series of 2009).

Provenance and peer review Not commissioned; externally peer reviewed. Data availability statement Data are available upon reasonable request.

Open access This is an open access article distributed in accordance with the Creative Commons Attribution Non Commercial (CC BY-NC 4.0) license, which permits others to distribute, remix, adapt, build upon this work non-commercially, and license their derivative works on different terms, provided the original work is properly cited, appropriate credit is given, any changes made indicated, and the use is non-commercial. See: http://creativecommons.org/licenses/by-nc/4.0/.

\section{REFERENCES}

1. World Health Organization. Sixty - Third World health assembly. Ca report by the Secretariat, A63/10. Geneva, Switzerland: World Health Organization, 2010.

2. World Health Organization. Global health Observatory (GHO) data. Under-five mortality, 2016. Available: http://www.who.int/gho/child health/mortality/mortality_under_five_text/en/ [Accessed 12 Dec 2017].
3. Christianson AL, Howson CP, Modell B. Global report on CA: the hidden toll of dying and disabled children. White Plains (NY): March of Dimes Defects Foundation, 2006.

4. Tennant PWG, Pearce MS, Bythell M, et al. 20-Year survival of children born with congenital anomalies: a population-based study. The Lancet 2010;375:649-56.

5. Wang Y, Hu J, Druschel CM, et al. Twenty-five-year survival of children with birth defects in New York state: a population-based study. Birth Defects Research;201:995-1003.

6. HS K, Kim DJ, Chung Y, et al. A national cohort study evaluating infant and fetal mortality caused by birth defects in Korea. BMJ Open 2017:7:e017963.

7. Botto LD, Mastroiacovo P. Triple surveillance: a proposal for an integrated strategy to support and accelerate birth defect prevention. Ann N Y Acad Sci 2018;1414:126-36.

8. Avni FE, Maugey-Laulom B, Cassart M, et al. Foetal genitourinary tract. In: Callen PW, ed. Ultrasonography in obstetrics and gynecology. 5th edn. New York: W.B. Saunders, 2007: 640-75.

9. Metzger BE, Gabbe SG, Persson B, et al. International association of diabetes and pregnancy study groups recommendations on the diagnosis and classification of hyperglycemia in pregnancy: response to Weinert. Diabetes Care 2010;33:e98-82.

10. EUROCAT. Eurocat guide 1.3. Instructions for registration and surveillance of congenital anomalies. Belfast, Northern Ireland University of Ulster, 2005. Available: http://www.eurocat-network.eu/ content/Section\%202.4-\%2027_Oct2016.pdf

11. EUROCAT. Prevalence tables, 2011-2015, 2015. Available: http:// www.eurocat-network.eu/newprevdata/showPDF.aspx? winx $=18968$ winy $=940 \&$ file=allsubgroups.asp $x$ [Accessed 12 Dec 2017].

12. Springett A, Budd J, Draper ES, et al. Congenital anomaly statistics 2012 England and Wales, London, 2014. Available: www.binocar.org/ content/Annual\%20report\%202012_FINAL_nologo.pdf

13. Sheridan E, Wright J, Small N, et al. Risk factors for congenital anomaly in a multiethnic birth cohort: an analysis of the born in Bradford study. Lancet 2013;382:1350-9.

14. Al Bu Ali WH, Balaha MH, Al Moghannum MS, et al. Risk factors and birth prevalence of birth defects and inborn errors of metabolism in al Ahsa, Saudi Arabia. Pan Afr Med J 2011;8.

15. Fida NM, Al-Aama J, Nichols W, et al. A prospective study of congenital malformations among live born neonates at a university hospital in Western Saudi Arabia. Saudi Med J 2007:28:1367-73.

16. Refat MY, Al-Moghanem M, McDonald P, et al. Major birth defects at King Fahd Hofuf Hospital: prevalence, risk factors and outcome. Ann Saudi Med 1995;15:339-43.

17. Sallout B, Obedat N, Shakeel F, et al. Prevalence of major congenital anomalies at King Fahad medical City in Saudi Arabia: a tertiary care centre-based study. Ann Saudi Med 2015;35:343-51.

18. Kancherla V, Oakley GP, Brent RL. Urgent global opportunities to prevent birth defects. Semin Fetal Neonatal Med 2014;19:153-60.

19. Youngblood ME, Williamson R, Bell KN, et al. 2012 update on global prevention of folic acid-preventable spina bifida and anencephaly. Birth Defects Res A Clin Mol Teratol 2013;97:658-63.

20. Kingdom of Saudi Arabia, Ministry of health. Nutritional department directive Number 652/1/26, 2000.

21. Food fortification initiative, 2013. Available: http://www.ffinetwork. org/country_profiles/country.php?record=194 [Accessed 12 Dec 2017].

22. Kitzmiller JL, Wallerstein R, Correa A, et al. Preconception care for women with diabetes and prevention of major congenital malformations. Birth Defects Res A Clin Mol Teratol 2010;88:791-803.

23. Simeone RM, Devine OJ, Marcinkevage JA, et al. Diabetes and congenital heart defects: a systematic review, meta-analysis, and modeling project. Am J Prev Med 2014;48:195-204.

24. Al-Nuaim AR, Al-Rubean K, Al-Mazrou Y. Prevalence of diabetes mellitus, obesity and hypercholesterolemia in Saudi Arabia: national chronic disease survey. ISBN: 1995; 9960-603-01-6. Riyadh (KSA): Ministry of health and King Saud university, 1995.

25. El-Hazmi M, Warsy A, Al-Swailem AR, et al. Diabetes mellitus as a health problem in Saudi Arabia. East Mediterr Health J 1998:58-67.

26. Warsy AS, el-Hazmi MA. Diabetes mellitus, hypertension and obesity--common multifactorial disorders in Saudis. East Mediterr Health J 1999;5:1236-42.

27. Al-Nozha MM, Al-Maatouq MA, Al-Mazrou YY, et al. Diabetes mellitus in Saudi Arabia. Saudi Med J 2004;25:1603-10.

28. El-Mouzan MI, Al-Salloum AA, Al-Herbish AS, et al. Regional variations in the prevalence of consanguinity in Saudi Arabia. Saudi Med J 2007;28:1881-4.

29. Hamamy H. Consanguineous marriages : preconception consultation in primary health care settings. $J$ Community Genet 2012;3:185-92. 
30. Majeed-Saidan MA, Ammari AN, AlHashem AM, et al. Effect of consanguinity on birth defects in Saudi women: results from a nested case-control study. Birth Defects Res A Clin Mol Teratol 2015;103:100-4.

31. Mak CM, Lee H-CH, Chan AY-W, et al. Inborn errors of metabolism and expanded newborn screening: review and update. Crit Rev Clin Lab Sci 2013;50:142-62.

32. Moammar H, Cheriyan G, Mathew R, et al. Incidence and patterns of inborn errors of metabolism in the eastern Province of Saudi Arabia, 1983-2008. Ann Saudi Med 2010;30:271-7.

33. Loane M, Dolk H, Morris JK, et al. Maternal age-specific risk of Nonchromosomal anomalies. BJOG 2009;116:1111-9.

34. Nabukrea S, Wingate MS, Alexander GR, et al. First -time births among women 30 years and older in the United States: patterns and risk of adverse outcome. J Reprod Med 2006;9:676-82.
35. Goetzinger KR, Shanks AL, Odibo AO, et al. Advanced maternal age and the risk of major congenital anomalies. Am J Perinatol 2017;34:217-22.

36. U.S. Preventive Services Task Force. Folic acid for the prevention of neural tube defects: U.S. preventive services Task force recommendation statement. Ann Intern Med 2009;150:626-31.

37. Al Rakaf MS, Kurdi AM, Ammari AN, et al. Patterns of folic acid use in pregnant Saudi women and prevalence of neural tube defects - results from a nested case-control study. Prev Med Rep 2015;2:572-6.

38. Majeed-Saidan MA, Kashlan FT, Al-Zahrani AA, et al. Pattern of neonatal and postneonatal deaths over a decade (1995--2004) at a Military Hospital in Saudi Arabia. Saudi Med J 2008;29:879-83. 